\title{
GPPS-CH-2020-0025
}

\section{A FUNDAMENTAL STUDY ON A GAS TURBINE SYSTEM WITH OVERGROUND COMPRESSED AIR ENERGY STORAGE (CAES) FOR LOAD FOLLOWING}

\author{
Hiroki Nonomura \\ Fracture and Reliability Research Institute \\ Tohoku University \\ hiroki.nonomura@rift.mech.tohoku.ac.jp \\ Sendai, Miyagi, Japan
}

\author{
Susumu Nakano \\ Tohoku University \\ susumu.nakano@rift.mech.tohoku.ac.jp \\ Sendai, Miyagi, Japan
}

\author{
Yoichi Takeda \\ Tohoku University \\ takeda@rift.mech.tohoku.ac.jp \\ Sendai, Miyagi, Japan
}

\begin{abstract}
Herein, we propose an overground compressed air energy storage (CAES) equipped with a power absorption function in existing gas turbine systems to stabilize the power grid system when increasing the output power of variable renewable energy sources. The proposed system comprises a storage tank for storing compressor discharge air, intermediate compressor for boosting the reserved air to a higher pressure, and discharge tank for storing the boosted air. The operation method is described in detail and verified by our dynamic simulator for medium-capacity gas turbines. By providing storage and discharge tanks with a diameter of $18 \mathrm{~m}$ and extracting or discharging $10 \%$ of rated inlet airflow rate of the compressor, approximately extracting $9.3 \%$ and discharging $10.4 \%$ of rated electric energy of the turbine system can be achieved, respectively. It is encouraging that the overground CAES system can implement load following function with power absorption to existing gas turbine systems.
\end{abstract}

\section{INTRODUCTION}

Recently, renewable energy was introduced with the aim of reducing $\mathrm{CO}_{2}$ emissions and non-renewable fuel consumption worldwide and its use is also gaining popularity in Japan. However, variable renewable energy sources such as solar and wind power are difficult to adjust to the power demand because the output depends on the weather. In addition, a problem arises if surplus power must be absorbed from the power grid to stabilize the systems when they are installed in large numbers. Pumped hydropower generation is a load-following power source that can supply power while absorbing surplus power. It can store energy by pumping water back to the reservoir which becomes potential energy. In Japan, however, it is challenging to install pumped hydropower facilities. Conversely, compressed air energy storage (CAES) (Wang, et al., 2017) is a system that uses the same concept as pumped hydropower generation to store energy in the form of compressed air using surplus power. It generates power with a gas turbine to discharge compressed air stored during power demand.

CAES typically uses a gas turbine system in which the compressor and turbine have separate rotating shafts. It requires a huge underground salt cave to store compressed air. When power demand increases, the system generates electricity by releasing compressed air into the gas turbine without the compressor operation. As with pumped-storage power generation, surplus power generated by renewable energy sources can be used effectively. Additionally, when there is an urgent demand for power, the load-following operation can be easily realized by rapidly supplying stored compressed air and increasing the generated power. Though CAES has been commercially implemented in two cases worldwide (Lund, et al., 2009), this is not possible in Japan as it lacks the required thick rock salt layer that can form a large space.

In this study, the concept of a gas turbine system with an overground CAES is demonstrated by installing air storage tanks on the ground for an existing gas turbine system. 
Although practical applications are limited, as a fundamental study of the system, its basic configuration and operation methods are proposed. Effectiveness of the overground CAES system to extend load operation range of an existing turbine system is discussed.

\section{ISSUES ASSOCIATED WITH THE INCREASE OF RENEWABLE ENERGY SYSTEMS}

It is believed that the balance between power demand and supply will be lost with the installation of large numbers of variable renewable energy sources power plants. To stabilize the power grid system, it is necessary to secure the reserve power for power supply and frequency adjustment. As the use of variable renewable energy sources increases, significant fluctuations beyond the adjustment range are introduced in the system. In particular, when power generation exceeds demand, a function to absorb power from the electric grid is required. In addition, in Japan domestic power demand is reduced for approximately $1 \mathrm{~h}$ during lunchtime. Figure 1 shows the daily power demand curves in the North-Eastern parts of Japan in summer and winter (Tohoku Electric Power Network Co., Inc, 2019). The solid lines represent monthly average demand. A defined drop-off of power demand during lunchtime in each season can be observed. This is also the time when power generation from sunlight increases. The Tohoku Electric Power Network company which transmits the electricity in that region has set two facilities of large-scale battery energy storage systems whose capacity is $40 \mathrm{MWh}$ (Tohoku Electric Power Network Co., Inc, 2016). One of the facilities is operated for power absorption during lunchtime and power discharge after lunchtime. Here, the application of the ground-based CAES system to the existing gas-fired power generation system is considered to create a system with the same function as battery storage.

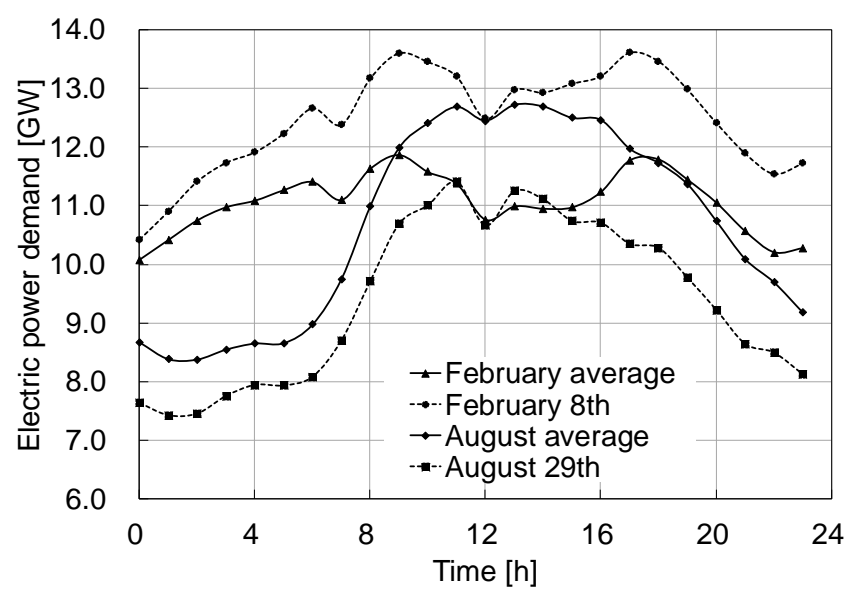

Figure 1 Electric Power Demand Curves

\section{OVERGROUND CAES SYSTEM}

\section{Basic configuration}

In the existing CAES systems, because the rotor shafts of the compressor and turbine have different shafts or can be separated, they can operate independently. Conversely, in existing gas turbines for power generation, the compressor and turbine usually share the same rotating shaft; thus, they are not suitable to be operated independently. For this reason, it is difficult to apply overground CAES to the existing gas turbine for power generation.

Figure 2 shows a schematic diagram of the overground CAES. It consists of a two-spherical tank system, composed of the storage and discharge tanks. An intermediate compressor can be installed between these tanks, and the air extracted from the compressor in the turbine system can be further pressurized and stored in the discharge tank.

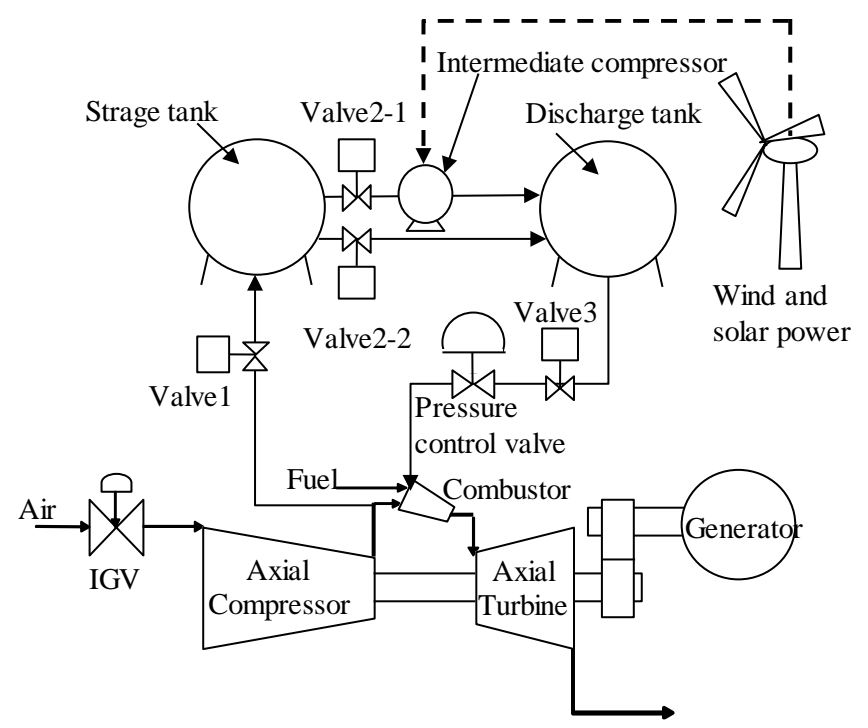

Figure 2 Schematic the Overground CAES System

\section{How to operate of overground CAES system}

The entire operation procedure of the CAES system is outlined here. The operation is explained using the compressor characteristic curve. Figure 3 shows the pressure-flow characteristic curve of the compressor used in the existing gas turbine system for power generation (Kashiwabara, et al., 1990). According to the decrease of the electric power demand, gas-fired power plants are usually commanded to decrease their outputs. First, the generation output power is decreased from the rated output power shown as point (4) to $50 \%$ of the load state shown as point (1) in Figure 3, along the curve of the rated rotational speed. Then, the fuel flow rate and the pressure of the compressor discharge are decreased. Subsequently, CAES operation for extracting the compressor discharge air, which denotes the starting operation of valve1 and valve2-1. The intermediate compressor of the CAES system as shown in Figure 2, is started. Assume that $10 \%$ of the compressor discharge air at the $50 \%$ load operating point (1) in Figure 3 is extracted and stored in the storage tank of the CAES system. As the mass flow rate of air sent to the turbine is $90 \%$ of the compressor discharge air, the operating point of the turbine moves to point (2), along with the turbine characteristic line when the combustion temperature remains constant. As the turbine-corrected flow rate was almost constant within the current operating range, the turbine inlet pressure was calculated based on it.

When supplying air from the CAES, the inlet guide valve (IGV) opening is throttled in advance because the turbine 
system has been operated at $50 \%$ load, and the compressor inlet flow rate is decreased to reduce the power generation output. The performance curve of the compressor when the IGV opening is changed at the rated rotational speed $(100 \%$ rotational speed) moves to the dashed line in Figure 3 (Ikui and Inoue, 1988). The turbine operation point must be changed from the partial load operation point (2) to the $100 \%$ load point (4). Regarding the flow rate, the rated air flow rate is ensured with the compressor discharge airflow rate of $90 \%$ and supply airflow rate of $10 \%$ from CAES. The compressor operating point is also changed from point (2) to (3) because the performance curve of the compressor is maintained in the dashed line, as shown in Figure 3, due to the throttled IGV opening and the compressor discharge pressure rises due to the turbine work increase. The pressure at points (2) and (4) differs, whereas the air in the storage tank cannot be supplied directly to the combustor, which necessitates boosting the pressure with the intermediate compressor. The driving power of the latter consumes surplus power from renewable energy sources to stabilize the power grid.

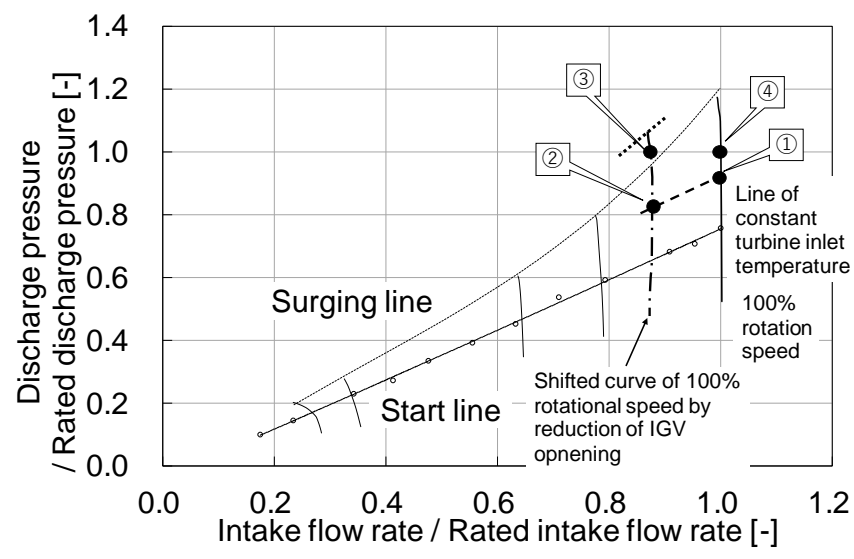

\section{Figure 3 Compressor Characteristic Curve and CAES Operating Point}

\section{CALCULATION METHOD}

\section{Target Gas Turbine System for CAES Installation}

As some performance data are disclosed (Kashiwabara, et al., 1990) and some actual operation data of the power plant can be referred, a medium-capacity gas turbine system with the rated outpower of approximately $36 \mathrm{MW}$ is selected as the target gas turbine system for the CAES installation. The dynamic simulator for an axial turbine is modified and developed for microturbines (Seki, et al., 2015), (Suzuki, et al., 2017). Only the outline of the calculation method is briefly described here. The motion of the turbine rotor is expressed by an equation of conservation of angular momentum. This equation can be rewritten to the relationship with the angular velocity and works acting on the turbine rotor.

$$
\frac{d \omega^{2}}{d t}=\frac{2}{I}\left(W_{T}-W_{C}-W_{G}-W_{\text {loss }}\right) .
$$

The driving power of the compressor, the output power of the turbine, and total loss of the rotor in the right-hand side of
$\mathrm{Eq}(1)$ are calculated as steady conditions because the state change of each component in the infinitesimal time dt can be assumed to be quasi-steady. The driving power of the compressor is calculated by using the pressure ratio between the outlet and the inlet of the compressor.

$$
W_{C}=m_{C} c_{p, C} T_{i n, C}\left\{\left(\frac{P_{e x, C}}{P_{i n, C}}\right)^{\frac{\kappa-1}{\eta_{p l, C}}}-1\right\}
$$

where the inlet flow rate is determined by the IGV opening, the rotational speed of the turbine rotor, and the characteristic curves of the compressor shown in Figure 3. The polytropic efficiency is referred to as the data of the target gas turbine (Kashiwabara, et al., 1990). The output power of the turbine is also calculated by the pressure ratio and polytropic efficiency.

$$
W_{T}=m_{T} c_{p, T} T_{i n, T}\left\{1-\left(\frac{P_{e x, T}}{P_{i n, T}}\right)^{\eta_{p l, T} \frac{\kappa-1}{\kappa}}\right\}
$$

The inlet temperature of the turbine is determined by the enthalpy of the combustion gas. As the polytropic efficiencies of the target turbine system are not disclosed to the public, they are assumed using the relationship in Eq. (4) and the adiabatic efficiencies referred to Smith's chart (Moustapha, et al., 2003).

$$
\eta_{p l, T}=\frac{\kappa}{\kappa-1} \frac{\ln \left\{1-\eta_{a b, T}\left(1-\left(\frac{P_{e x, T}}{P_{i n, T}}\right)^{\frac{\kappa-1}{\kappa}}\right)\right\}}{\ln \left(\frac{P_{e x, T}}{P_{i n, T}}\right)}
$$

Total loss of the rotor motion is assumed to the summation of the bearing and windage losses. Therefore, the output of the generator is deduced from the balance of Eq. (1).

\section{Overground CAES System}

To better understand the basic capacity of the CAES facility, we set the duration of both storage of compressor discharge air and release of tank air to $1 \mathrm{~h}$ set based on the daytime power demand decline period. Tanks with a diameter of $18 \mathrm{~m}$ and compressor with a pressure ratio of four were determined; therefore, $1 / 10$ of the rated inlet mass flow rate of the compressor could be supplied to the turbine system for more than $1 \mathrm{~h}$ during the CAES operation. Performance curves of the intermediate compressor are based on (Nakano, et al., 2007) of the existing centrifugal compressor, and the flow rate is corrected to $1 / 10$ of the rated mass flow rate of the turbine system compressor. Figure 4 shows the performance curve. It was assumed that the intermediate compressor was boosted along the running line for $300 \mathrm{~s}$ after initiated and moved on to the performance curve of $100 \%$ rotation with a load on the discharge side after reaching the rated rotational speed. The duct diameter of the piping system was set $0.14 \mathrm{~m}$.

Density and temperature in the tanks are calculated using conservation equations of mass and energy. 


$$
\begin{gathered}
V_{s t} \frac{d \rho_{s t}}{d t}=m_{1}-m_{2} \\
V_{d s t} \frac{d \rho_{d s t}}{d t}=m_{2}-m_{3} \\
V_{s t} \frac{d\left(c_{p} \rho_{s t} T_{s t}\right)}{d t}=m_{1} c_{p} T_{e x, C}-m_{2} c_{p} T_{s t}-Q_{l, s t} \\
V_{d s t} \frac{d\left(c_{p} \rho_{d s t} T_{d s t}\right)}{d t}=m_{2} c_{p} T_{s t}-m_{3} c_{p} T_{d s t}-Q_{l, d s t} .
\end{gathered}
$$

In the energy conservation equations, heat transfer and heat radiation from the tank surface as a heat loss are considered. Air pressure in the tank is calculated with the density and the temperature using the state equation. Each mass flow rate to or from the tank is calculated by the pressure ratio between inside and outside of the tank.

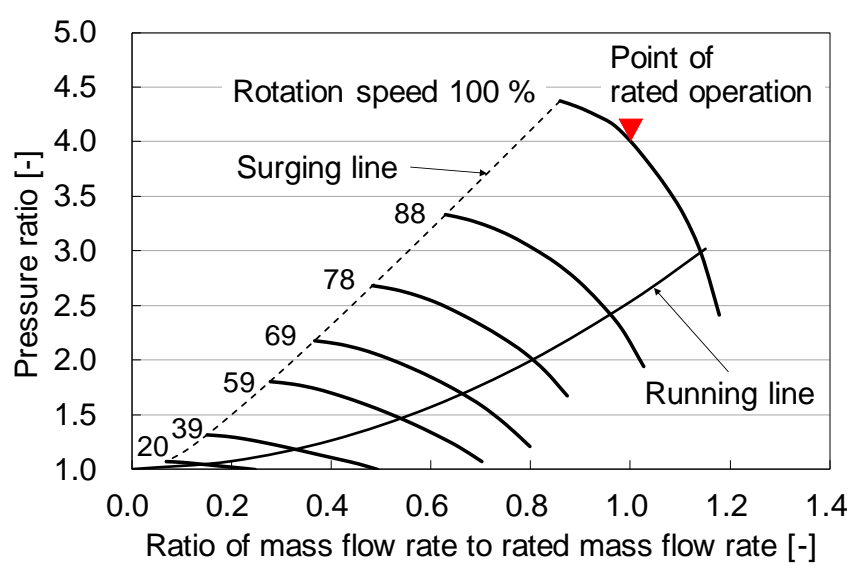

\section{Figure 4 Characteristics Curves of Intermediate Compressor}

\section{CALCULATION CONDITIONS}

The dynamic simulator requires three types of input data to calculate turbine operation. The rotational speed of the turbine rotor, fuel flow rate, and IGV opening are given as the input data. Calculations are performed for two cases, which are extracting the compressed air from the exit of the turbine system compressor and supplying air from the discharge tank. In each calculation, within $0.5 \mathrm{~h}$ from the start, actual load change operation performed in a real power plant installed the target turbine is reproduced. Calculation accuracy was confirmed to compare the measured results in the power plant. Atmospheric conditions of the turbine operation are as follows: pressure $=102 \mathrm{kPa}$ and temperature $=6{ }^{\circ} \mathrm{C}$.

\section{Extracting compressor discharge air}

When the gas turbine system operates at $50 \%$ load, the compressor discharge air of the turbine system is stored in the CAES system. As mentioned before, in the calculation, within $0.5 \mathrm{~h}$ from the start, actual load change operation performed in a real power plant installed the target gas turbine is reproduced, that is, IGV opening ratio at the rated rotational speed is set to the initial value of $68 \%$, then maintained at $100 \%$. A virtual start-up time of 0 to $0.08 \mathrm{~h}$ for short start-up time is defined due to simulation requirements and it is not important for the main discussion. As shown in Figure 5, after $0.5 \mathrm{~h}$, the fuel flow is reduced, leading to the reduction of power generation output by $50 \%$. The fuel flow rate was estimated using values at the no-load operation and the $100 \%$ output power operation. Subsequently, the CAES operation started; valves 1and 2-1 opened, and the intermediate compressor operated from the elapsed time of $0.79 \mathrm{~h}$. The fuel flow rate decreased more with the reduction of the combustion airflow rate by the CAES operation to maintain the combustion gas temperature the same as one of the $50 \%$ load. The initial values for storage and discharge tanks were the same as the discharge pressure and temperature of the turbine system compressor during the $50 \%$ load operation.

In Figure 5, approximately $0.5 \mathrm{~h}$ (elapsed time $1.29 \mathrm{~h}$ ) after the CAES operation, the fuel flow rate was increased to return the generator output power to the $50 \%$ load.

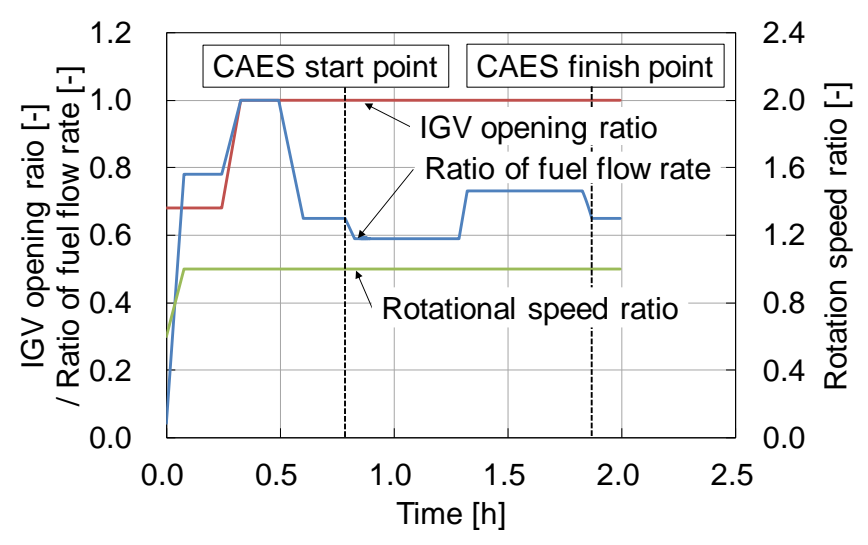

Figure 5 Input Data for the Operation of Extracting Compressed Air

\section{Supplying Air from The Discharge Tank}

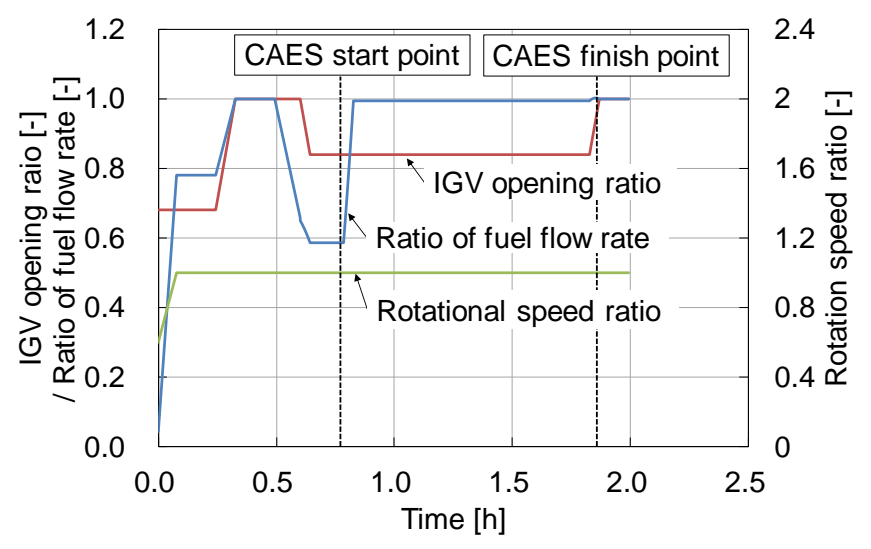

\section{Figure 6 Input Data for the Operation of Supplying} Air

As in the previous section, the calculation reproduces partial and rated load operation for the first $0.5 \mathrm{~h}$; subsequently, the start condition for the CAES operation is provided. The rotational speed of the gas turbine during the CAES operation is the same as in Figure 5. Figure 6 shows the IGV opening and fuel flow rate. After $0.5 \mathrm{~h}$, while the IGV opening did not 
change, the fuel flow is reduced, and generator output power decreased to $50 \%$ load, achieving the operation point (1) in Figure 3. Subsequently, the IGV opening ratio is decreased to $83 \%$ and the CAES operated in the operation state of point (2) as shown in Figure 3. Air is supplied from the discharge tank to the gas turbine combustor by opening valve 3 and pressure control valve after an elapsed time of $0.79 \mathrm{~h}$. After $1 \mathrm{~h}$ of the CAES operation, the IGV opening is recovered.

\section{ANALYSIS RESULTS AND DISCUSSION}

\section{Extracting Compressor Discharge Air}

Figure 7 shows the discharge pressure of the turbine system compressor and CAES tanks, which are normalized by the rated discharge pressure of the turbine system compressor.

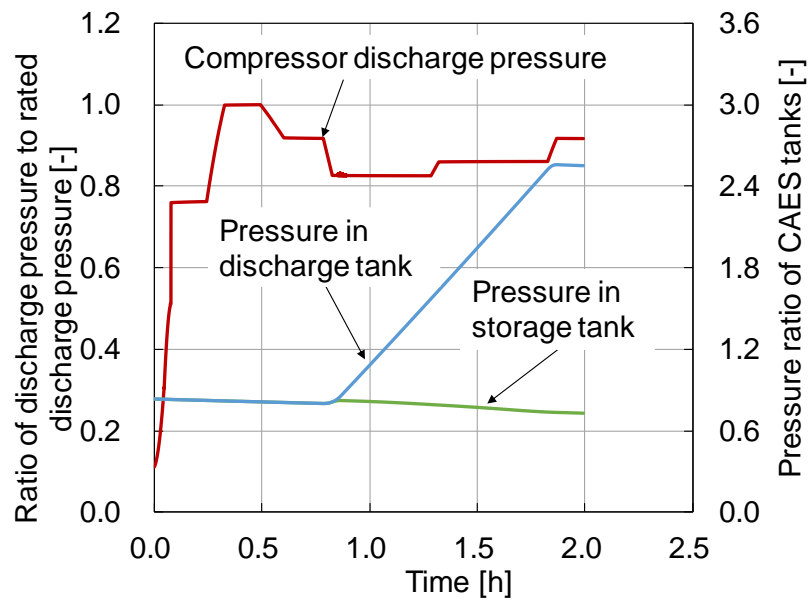

Figure 7 Pressure Change

The compressor discharge pressure of the turbine system indicated with (1) is the pressure at $50 \%$ load in the rated rotational speed shown in Figure 3. After the CAES start, when the airflow rate decreases while maintaining the combustion temperature unchanged, the turbine-corrected flow rate is constant, which lowers the compressor discharge pressure driving it to state (2). In this state, the generator output falls below $50 \%$ and returns to $50 \%$ after $1.29 \mathrm{~h}$. The fuel flow rate is increased as the turbine inlet temperature raised. The compressor discharge pressure increases slightly as the load increases. Pressures in storage and discharge tanks before the start point of the CAES slightly decrease due to heat dissipation from the tank surface. Pressure in the storage tank after the start of the intermediate compressor decreases because of the pressure drop caused by tank heat dissipation and the difference between the mass flow rate into the storage tank and the discharge mass flow rate of the intermediate compressor. Pressure in the discharge tank reaches more than 2.5 times the rated discharge pressure of the turbine system compressor with approximately $1 \mathrm{~h}$ operation of the intermediate compressor.

Figure 8 shows the changes in the compressor inlet mass flow rate, turbine inlet mass flow rate, and mass flow rate of the tanks. Although the compressor inlet flow rate does not change after the CAES operation, the flow rate of air sent to the turbine is reduced by approximately $10 \%$, which is stored in the tank of the CAES system. The airflow rate of the intermediate compressor is larger than the designed rated point. During $1 \mathrm{~h}$ of operation of the intermediate compressor, the pressure ratio of discharge and storage tanks is less than the rated pressure ratio of the intermediate compressor. This is because the inlet mass flow rate of the intermediate compressor exceeds the rated flow rate.

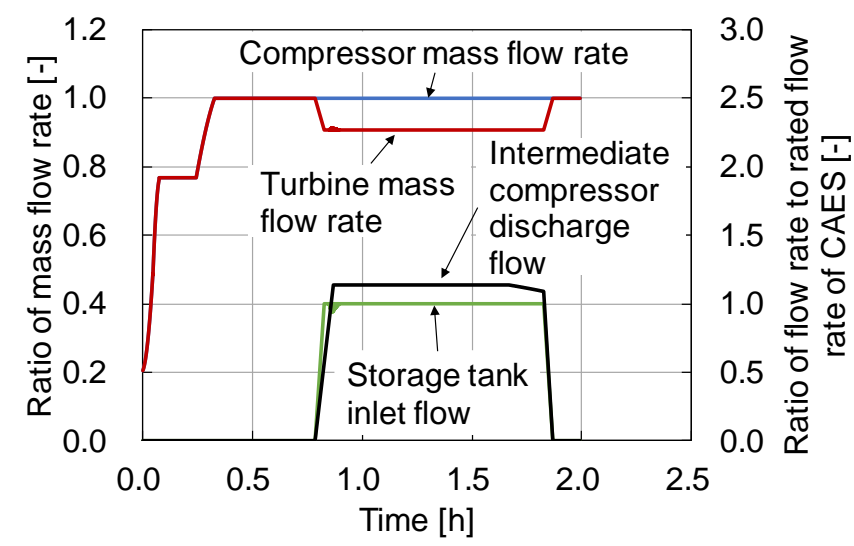

Figure 8 Mass Flow Rate

Figure 9 shows the turbine output, compressor power, and generator output. During the first half of the CAES operation, the previous combustion gas temperature is maintained, resulting in a decrease in the generator output caused by a decrease in the fuel flow rate. To return the generator output to $50 \%$, the fuel flow rate is increased after $1.29 \mathrm{~h}$. Figure 10 shows power ratio of the driving power of the intermediate compressor to the rated output power of the generator. The maximum power ratio of approximately 0.096 can be absorbed in $1 \mathrm{~h}$ extraction.

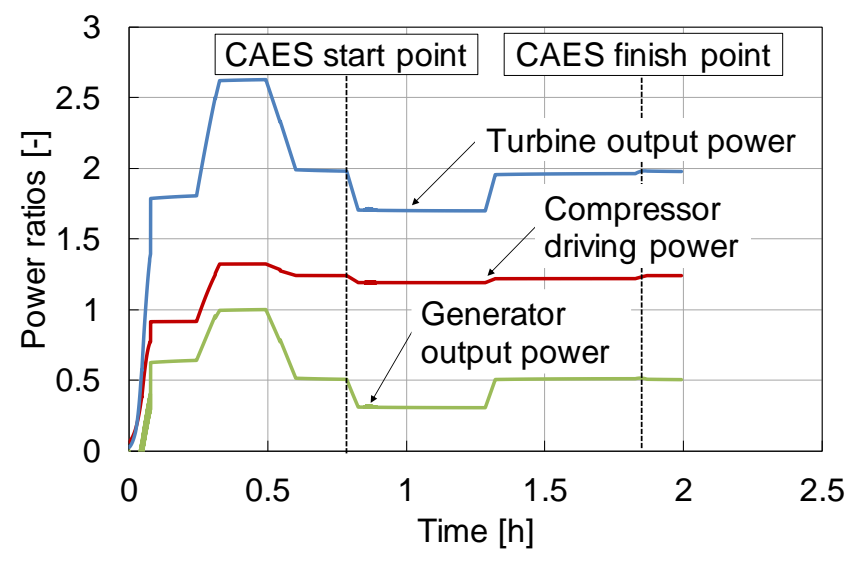

Figure 9 Comparison of Output Powers 


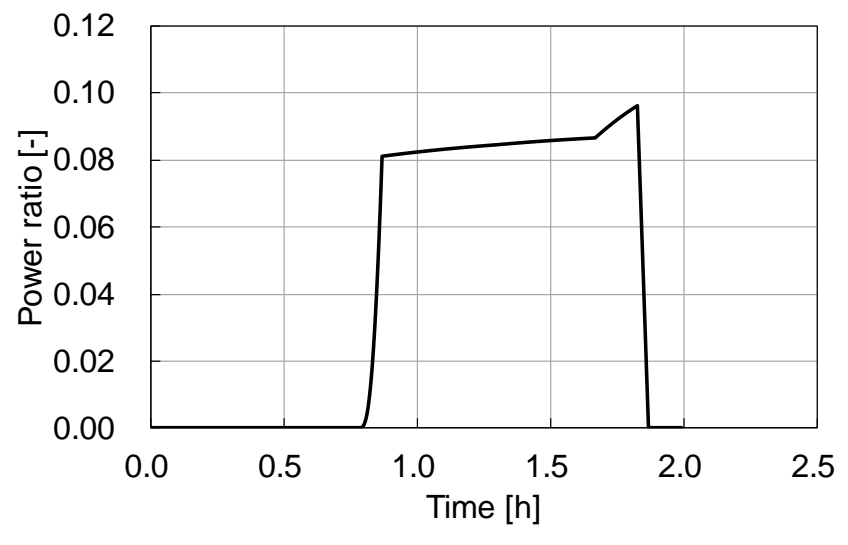

Figure 10 Intermediate Compressor Driving Power

\section{Supplying Air from The Discharge Tank}

The initial condition of the discharge tank is the same as the state after $1 \mathrm{~h}$ of filling by the intermediate compressor shown in Figure 7, during which the air will be supplied to the combustor. Figure 11 shows the pressure changes in the outlet of the turbine system compressor and in the discharge tanks. The pressure in the discharge tank is reduced to supply the airflow to the gas turbine. However, even after $1 \mathrm{~h}$ of air supply, the pressure is still higher than the rated discharge pressure of the turbine system compressor, where the air from the discharge tank to the gas turbine can be continued. The discharge tank with $18 \mathrm{~m}$ diameter possesses sufficient volume to store air for $1 \mathrm{~h}$ supply. The compressor discharge pressure changes from point (2) to point (3) shown in Figure 3 when CAES is activated and the turbine work increases along with an increase in mass flow rate of turbine inlet and fuel flow rate.

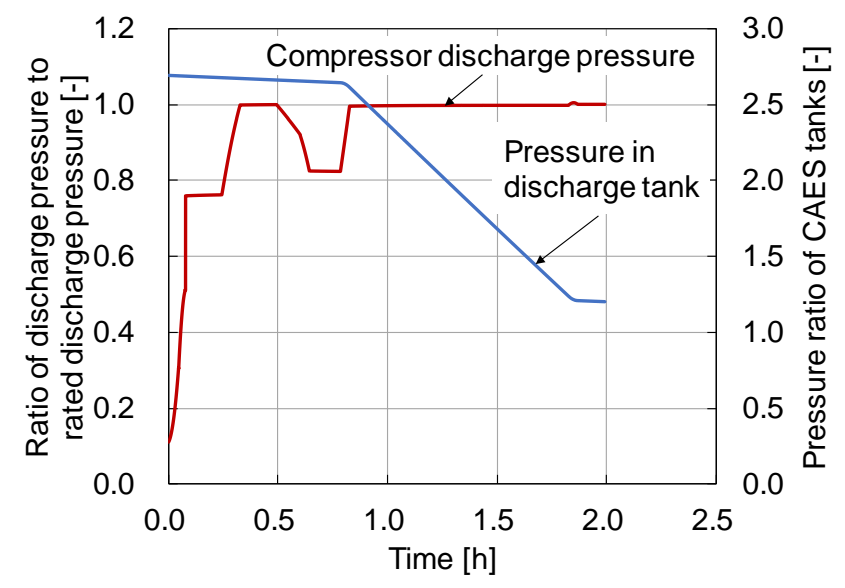

Figure 11 Pressure Changes of Tanks

Figure 12 shows the mass flow rates. The mass flow rate of compressor inlet during the CAES operation is approximately $90 \%$ of the rated mass flow rate of the turbine system compressor, but the mass flow supplied to the turbine during the CAES operation is secured the same as that during normal rated operation.

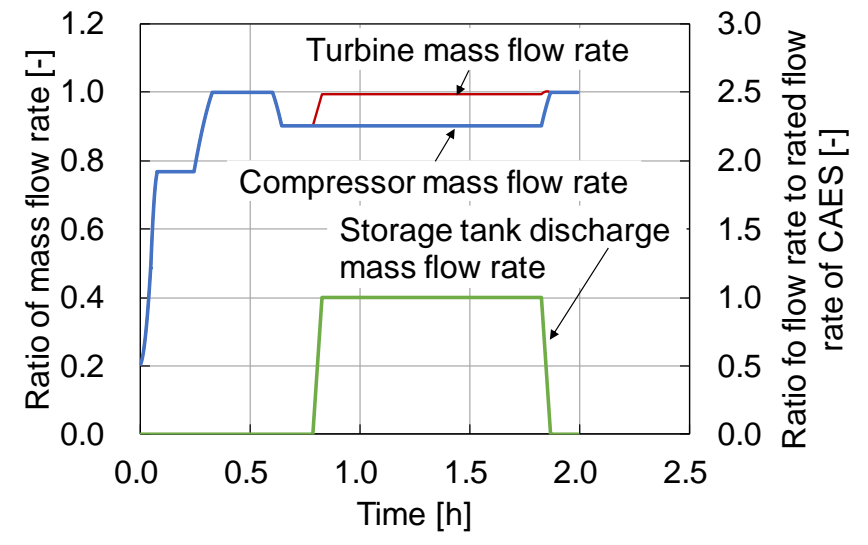

Figure 12 Mass Flow Rate

From Figure 13, the generated power during the CAES operation is approximately $10 \%$ higher than the normal rated output operation. When air is supplied by the CAES operation, the turbine output does not differ between operations of normal rated output and CAES. However, the compressor driving power is reduced by the inlet mass flow rate decrease of the turbine system compressor, which directly contributes to the increase in power generation output.

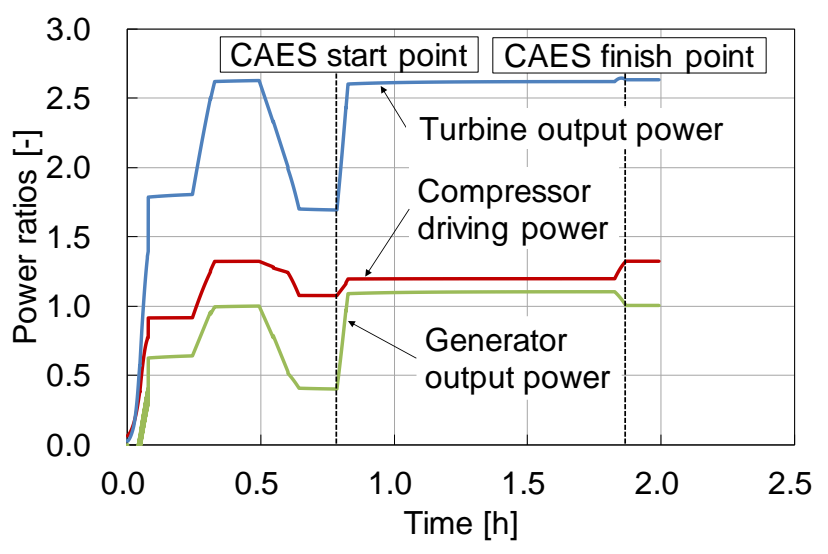

\section{Figure 13 Comparison of Output Powers}

\section{Power Generation Efficiency During CAES Operation}

We consider the power generation efficiency of the gas turbine system during the CAES operation. Figure 14 shows the power generation efficiency ratio, where it is calculated from dividing the generator output by the calorific value of the input fuel, and the power consumption of the intermediate compressor is not accounted. A result of one indicates the rated power generation efficiency of the turbine system without the CAES operation. Compared to the efficiency ratio of $50 \%$ load with and without the CAES operation, the efficiency ratio is reduced by approximately 0.09 . Conversely, the efficiency ratio when the power generation output is increased by supplying air from CAES shows that the power generation efficiency increases by approximately 0.11 compared to the normal $100 \%$ output. As the difference between gained and lost efficiencies, the efficiency ratio of the turbine system is improved by approximately 0.02 . 


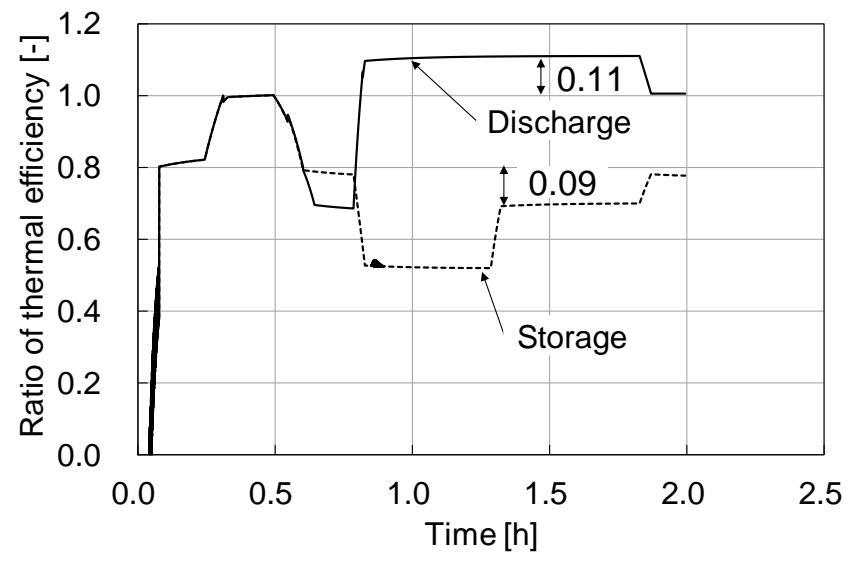
Figure 14 Thermal Efficiency during CAES
Operation

Next, we consider the absorbed and gained energy during the CAES operation. The absorbed energy is calculated as the energy consumption of the intermediate compressor. The calculation of the gained energy is evaluated by the difference between the rated electric energy of the generator and generated energy during the CAES operation for discharge air. The obtained calculation results are shown in Figure 15, where the absorbed and gained amounts normalized by the rated electric energy of the generator are 0.093 and 0.104 , respectively. When the $50 \%$ load operation is the minimum load of the turbine system, the load range can be extended to 1.4 times by the CAES operation. Comparing with the storage battery system (Tohoku Electric Power Network Co., Inc, 2016), the storage capacity of the overground CAES is approximately $1 / 10$. The operation of CAES must avoid compressor surge. The amount of air stored and released depends on the rated mass flow rate of the turbine system compressor. In this analysis, to avoid compressor surge, storage and discharge quantity were set to $10 \%$ of the rated inlet mass flow rate of the compressor. Although it depends on characteristic curves of a compressor, the basic function of the overground CAES system can be applied to other capacity turbine systems because extracting $10 \%$ of rated airflow rate might be executed in those without any modification. To increase energy absorption and supply, CAES must be applied to a larger capacity turbine system.

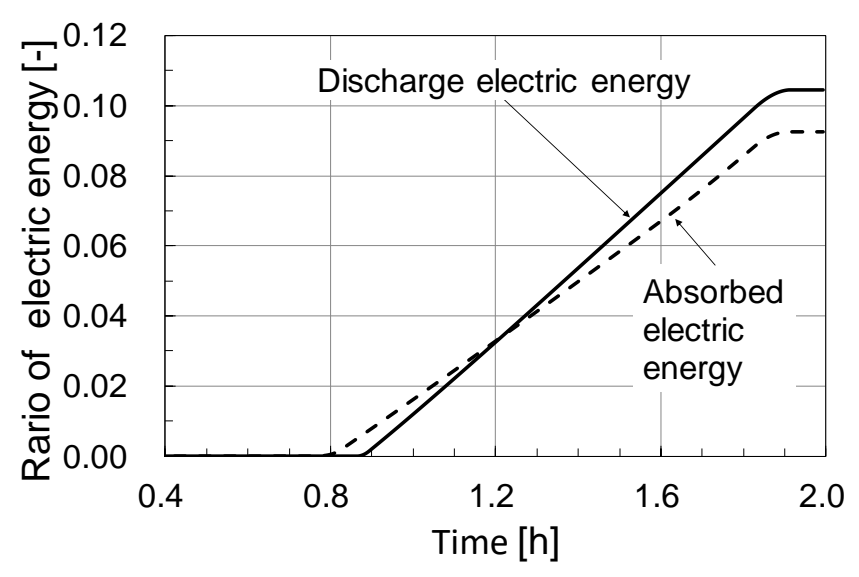

Figure 15 Absorbed and Discharged Electric Energy

\section{Charge/discharge efficiency of CAES}

When charge/discharge efficiency is defined as the overground CAES, the energy of discharge refers to the energy gained in the CAES operation. The energy required for charging is the energy required for air storage, which is the summation of the electric energy reduced by the CAES operation during the storage, and the amount of the intermediate compressor power. The energy reduction caused by the CAES operation during the storage is calculated as the difference between the output energy of the generator with and without the CAES operation on the same fuel flow rate conditions, which corresponds to approximately $10 \%$ of rated electric energy of the generator. From Figure 15, we can observe that the charge/discharge efficiency which is defined as the ratio of discharge energy to the required energy for the storage is approximately $54 \%$.

When air with a constant flow rate is supplied to the turbine for a certain period of time using the overground CAES, the total supply air mass is unchanged. Therefore, if the tank diameter increases, the relevant tank pressure decreases, and vice versa. The pressure in the discharge tank determines the driving power of the intermediate compressor because the driving power depends on the pressure ratio between the discharge and the storage tank. Thus, the charge/discharge efficiency depends on the tank diameter. In addition, it is desirable to increase the intermediate compressor energy with respect to the energy absorption from renewable energy sources. Figure 16 shows the calculation result of the charge/discharge efficiency as a function of the ratio of absorption to gained energy of the overground CAES for tank diameters of 14-27 m, together with another system for comparison (Crotogino, et al., 2001) (Lindley, 2010) (Rehmen, et al., 2015) (Schimpe, et al., 2018).

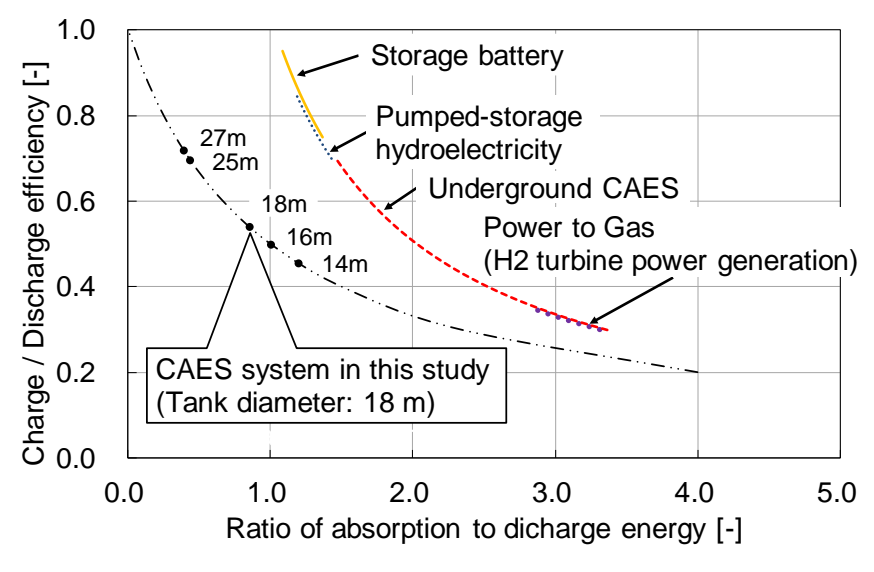

\section{Figure 16 Charging/Discharging Efficiency}

In the case of other systems, the ratio of the absorbed to the discharged energy on the horizontal axis is equal to the reciprocal of the charge/discharge efficiency on the vertical axis. However, in the overground CAES system, discharge energy is regarded as gained energy by the CAES operation during the discharge, and charge energy is regarded as total consuming energy to store compressed air, which is the summation of the intermediate compressor driving energy and 
energy reduction caused by the CAES operation during the storage. The absorption energy of the overground CAES system used in the horizontal axis is just the intermediate compressor driving energy. The ratio of the absorbed to the discharged energy on the horizontal axis is not equal to the reciprocal of the charge/discharge efficiency on the vertical axis. In the overground CAES, it is necessary to increase the tank diameter to increase the charge/discharge efficiency. However, a large tank diameter is not preferable owing to its high manufacturing cost. Increasing the tank diameter from 18 to $27 \mathrm{~m}$ increases the tank weight by approximately twice. Conversely, to absorb more surplus energy, it is necessary to increase the compression ratio of the intermediate compressor. However, as the tank diameter decreases, the pressure in the tank increases, and its temperature rises. In the case of $14 \mathrm{~m}$ diameter shown in Figure 16, air temperature in the discharge tank increases to approximately $900 \mathrm{~K}$. Considering the feasibility of the overground CAES system, the tank diameter should be in the range of 14-27 m. Charge/discharge efficiency of the overground CAES is comparable to those of storage battery, pumped-storage hydro, and underground CAES.

\section{CONCLUSION}

To stabilize the power grid system when the installation of renewable energy systems is increased, we proposed an overground CAES as a facility equipped with the power absorption function in the existing gas turbine system. This overground CAES system consists of a tank that stores the discharge air of the turbine system compressor (storage tank), an intermediate compressor that boosts the stored air to a higher pressure, and a tank that stores the pressurized air (discharge tank). In addition, an operation method for storing and releasing air from the CAES system was presented, and its operation was verified with the simulation of medium-capacity gas turbines operation. By installing storage and discharge tanks with a diameter of $18 \mathrm{~m}$ and extracting or discharging $10 \%$ of the rated inlet flow rate of the turbine system compressor, approximately $9.3 \%$ of rated electric energy of the generator can be absorbed and $10.4 \%$ gained. The load operation range of the turbine system can be extended to 1.4 times. This shows the proposed overground CAES system, which can absorb fluctuating output power from renewable energy sources, can introduce a load-following function to the existing gas turbine systems.

\section{NOMENCLATURE}

$\begin{array}{lll}\mathrm{c}_{\mathrm{p}} & \text { Specific heat with constant pressure } & {[\mathrm{J} /(\mathrm{kg} \mathrm{K})]} \\ \mathrm{I} & \text { Moment of inertia } & {\left[\mathrm{kgm}^{2}\right]} \\ \mathrm{m} & \text { Mass flow rate } & {[\mathrm{kg} / \mathrm{s}]} \\ \mathrm{P} & \text { Pressure } & {[\mathrm{Pa}]} \\ \mathrm{Q}_{1} & \text { Heat loss } & {[\mathrm{W}]} \\ \mathrm{T} & \text { Temperature } & {[\mathrm{K}]} \\ \mathrm{t} & \text { Time } & {[\mathrm{s}]} \\ \mathrm{V} & \text { Volume } & {\left[\mathrm{m}^{3}\right]} \\ \mathrm{W} & \text { Power, Work } & {[\mathrm{W}]} \\ \eta_{a b} & \text { Adiabatic efficiency } & {[-]} \\ \eta_{p l} & \text { Polytropic efficiency } & {[-]} \\ \kappa & \text { Specific heat ratio } & {[-]}\end{array}$

$\begin{array}{lll}\rho & \text { Density } & {\left[\mathrm{kg} / \mathrm{m}^{3}\right]} \\ \omega & \text { Angular velocity } & {[\mathrm{rad} / \mathrm{s}]}\end{array}$

\section{SUBSCRIPT}

$\begin{array}{ll}\text { C } & \text { Compressor } \\ \text { dst } & \text { Discharge tank } \\ \text { G } & \text { Generator } \\ \text { in } & \text { inlet } \\ \text { loss } & \text { Loss } \\ \text { st } & \text { Storage tank } \\ \text { T } & \text { Turbine } \\ 1 & \text { From compressor exit to storage tank } \\ 2 & \text { From storage tank to discharge tank } \\ 3 & \text { From discharge tank to combustor }\end{array}$

\section{ACKNOWLEDGMENTS}

This study was conducted in the joint research with Tohoku University and Tohoku Electric Power Co., Inc. The authors express their gratitude to the great supports of Tohoku Electric Power Co., Inc.

\section{Reference section}

Crotogino, F., Mohmeyer, K. and Scharf, R. (2001). Huntorf CAES: More than 20 Years of Successful Operation. Solution Mining Research Institute Spring 2001 meeting.

Ikui, T. and Inoue, M. (1988). Turbo Blower and Compressor. 2nd ed. Tokyo: CORONA Publishing Co., LTD. (in Japanese).

Kashiwabara, K., Katoh, Y., Ishii, H., Hattori, T., Matsuura, Y. and Sasada, T., (1990). Developments Leading to an Axial Flow Compressor for a 25 MW Class High Efficiency Gas Turbine. Proceedings of the ASME 1990 International Gas Turbine and Aeroengine Congress and Exposition, Paper No. 90-GT-238. doi.org/10.1115/90-GT-012.

Lindley, D. (2010). Smart grids: The energy storage problem. Nature, 463(7277), pp. 18-20. doi.org/ 10.1038/463018a.

Lund, H. and Salgi, G. (2009). The role of compressed air energy storage (CAES) in future sustainable energy systems. Energy Conversion and Management, 50, 5. doi.org/10.1016/j.enconman.2009.01.032.

Moustapha, H., Zelesky, M. F., Baines, N. C., and Japikse, D., (2003). Axial and Radial Turbines, Concept NREC.

Nakano, S., Kishibe, T., Araki, H., Yagi, M., Tsubouchi, K., Ichinose, M., Hayasaka, Y., Sasaki, M., Inoue, T., Yamaguchi, K. and Shiraiwa, H. (2007). Development of a $150 \mathrm{~kW}$ microturbine system which applies the Humid Air Turbine Cycle. Proceedings of ASME Turbo Expo. Paper No. GT-200728192. doi.org/10.1115/GT2007-28192.

Rehman, S., Al-Hadhrami, Luai M., Alam, Md Mahbub. (2015). Pumped hydro energy storage system: A technological review. Renewable and Sustainable Energy Reviews. Paper No. 44 (2015) 586-598. doi.org/10.1016/j.rser.2014.12.040. 
Schimpe, M., Naumann, M., Truong, N., Hesse, Holger C., Santhanagopalan, S., Saxon, A., Jossen, A. (2018). Energy efficiency evaluation of a stationary lithium-ion battery container storage system via electro-thermal modeling and detailed component analysis. Applied Energy. Volume 210, pp. 211-229. doi.org/10.1016/j.apenergy.2017.10.129.

Seki, K., Nakano, S. and Takeda, Y. (2015). Dynamic Simulations of Microturbines. Proceedings of International Gas Turbine Congress, Paper No. IGTC2015-TuAMD.3.

Suzuki, K., Nakano, S., Seki, K., Takeda, Y. and Kishibe, T. (2017). Effects of Water Injection on Generator Output Power Augmentation in a Microturbine. Proceedings of International Symposium on Transport Phenomena and Dynamics of Rotating Machinery ISROMAC 2017.

Tohoku Electric Power Network Co., Inc. (2016). Minamisoma substation supply / demand balance improvement storage battery system demonstration project outline of results. Tohoku Electric Power Co., Inc. Official Website. Available at: http://www.nepc.or.jp/topics/pdf/170331/170331_1.pdf [Accessed at 26 Apr. 2020].

Tohoku Electric Power Network Co., Inc. (2019). Download past performance data. Tohoku Electric Power Co., Inc. Official Website. Available at: https://setsuden.nw.tohokuepco.co.jp/download.html [Accessed at 17 Apr. 2020].

Wang, J., Lu, K., Ma, L., Wang, J., Dooner, M., Miao, S., Li, J. and Wang, D. (2017). Overview of Compressed Air Energy Storage and Technology Development. Energies, 10, 991. doi.org/ 10.3390/en10070991. 